\title{
Using Educational Robotics as a Cognitive Tool for ICT Teachers in an Authentic Learning Environment
}

\author{
Adem Uzun ${ }^{1}$ \\ ${ }^{1}$ Department of Computer Education and Instructional Technologies, Bursa Uludag University, Turkey \\ Correspondence: Adem Uzun, Department of Computer Education and Instructional Technologies, Bursa Uludağ \\ Üniversitesi Görükle Yerleşkesi, Eğitim Fakültesi A Blok, 16059, Nilüfer, Bursa, Turkey. E-mail: \\ auzun@uludag.edu.tr
}

Received: December 2, 2019

Accepted: January 10, 2020

Online Published: February 27, 2020

doi:10.5539/ies.v13n4p27

URL: https://doi.org/10.5539/ies.v13n4p27

\begin{abstract}
This study describes the theoretical foundations of a learning environment designed for an ICT teachers' graduate level course, and presents a comprehensive analysis of the qualitative data acquired regarding the course's implementation. Participants in the study included six ICT teachers enrolled in the "Embedded Systems and Robotic Applications" course of Spring 2018. A design-based research approach was used in order to achieve a systematic but flexible methodology. Within the scope of this study, robotics was used as a cognitive tool, and authentic learning principles were applied. The participants' reflections about the learning environment indicated that they were satisfied with the course settings, their motivation increased after the course, and they learned more effectively through the scaffolding provided by the instructor.
\end{abstract}

Keywords: authentic learning, cognitive tools, educational robotics

\section{Introduction}

The use of digital technologies as cognitive tools has been found to facilitate learners' cognitive activities in support of their learning (Derry, 1990; Jonassen, 1994; Jonassen, Campbell, \& Davidson, 1994; Lajoie \& Derry, 1993). Expanding upon Salomon, Perkins, and Globerson's (1991) concept, "the effects of technology" versus "the effects with technology," Jonassen (1994) emphasized instead the distinction between "learning from or through technology" and "learning with technology." Jonassen also offered rationales for using technology as cognitive tools, including the interchangeable roles of learners and designers, learners as thinkers, knowledge construction rather than repeating the teacher, reflective thinking, learning "with" rather than "from" technology, lack of intelligence in tools, and distributed cognitive processing. From Jonassen's point of view, traditional design and development processes should be criticized empirically and philosophically because it is impossible to predict the behavior of complex organisms like humans with high accuracy. Meaningful learning thus requires an intellectual partnership between learners and digital technologies, rather than being controlled by them. This partnership enhances learners' thinking and learning because dealing with the tasks afforded by these technologies results in the learners' mindful engagement.

Using technology as cognitive tools mainly focuses on pedagogy rather than technology. These tools scaffold many of the important aspects of learning such as articulation, reflection, and providing a knowledge construction in the learner's mind rather than reproducing the teacher's. In other words, they enable learners to take ownership of their own learning. This idea is underpinned by Dewey's Experience and Education (Dewey, 1938), and the theory of "situated cognition" (Brown, Collins, \& Duguid, 1989). While the former focuses on real-world learning contexts with the principals of "learning by doing," the latter is based on "cognitive apprenticeships."

Authentic learning is a pedagogical approach that has the same foundations as using technology as cognitive tools whereby students can develop robust knowledge that they can transfer to real-world practice. This allows students the same problem-solving experiences in learning environments that they might experience in real life (Herrington, Reeves, \& Oliver, 2014). A framework was proposed by Herrington, et al. (Herrington, et al., 2014) for authentic technology-based learning environments, including:

- Authentic contexts in real life settings

- Authentic tasks 
- Expert performances

- Multiple roles and perspectives

- Collaboration in knowledge construction

- Reflection

- Articulation

- $\quad$ Scaffolding

- $\quad$ Authentic assessment

Two important issues regarding the use of technology as cognitive tools relate to their selection and implementation. When the use of technology as cognitive tools was first suggested, the preliminary tools were expert systems, semantic networks, computer programming, databases, spreadsheets, multimedia/hypermedia applications, conferencing systems, and microworld learning environments. As a result of technological advancements, however, the internet has significantly changed the educational technology landscape. Likewise, web 2.0 technologies have subsequently changed the way the internet is used in educational contexts including the integration of mobile technologies, embedded computer devices, and virtual and augmented reality.

As a result of these developments, one of the technological tools that emerged in learning environments is educational robotics. The use of robots in education at all levels, from kindergarten to higher education, has attracted the attention of many researchers and trainers due to recent developments in hardware and software tools (Alimisis, 2013; Xia \& Zhong, 2018). Even though robotics in education have been widely used in STEM/STEAM (Science, Technology, Engineering, and Mathematics/Science, Technology, Engineering, Arts, and Mathematics), it is still in an interdisciplinary position in many other fields and has the potential to be used in different learning areas (Ardito, Czerkawski, \& Scollins, 2020; Lindsay, 2020; Zhong \& Xia, 2020). According to Eguchi (2010), the most important factor underlying the use of robots in education as a unique learning tool is that it ensures an attractive learning environment by providing practical and entertaining activities based on real life, and thus stimulates the students' interest and curiosity. According to Benitti (2012), the use of robots in education contributes to the development of 21st-century skills such as research, creative thinking, decision making, problem solving, communication, and collaboration. In recent years, there has been an increase in the use of robots in STEM education. The results of the research on robotics in STEM education also show that such practices improve learners' creative thinking and problem-solving skills, make learning fun, promote positive attitudes, and increase motivation toward education (Karim, Lemaignan, \& Mondada, 2015; Mosley, Ardito, \& Scollins, 2016; Özdemir, Çelik, \& Öz, 2009).

Parallel to the developments in hardware and software tools, there is a significant increase in the robotic kits being introduced by the electronics industry including Lego Mindstorms, Arduino, TinyLab, M-Bot, Cubetto, and BeeBot. However, in Europe, the use of robots in education has not yet been sufficiently integrated into the teaching curricula (Alimisis, 2013). Robotic applications in education are generally observed as out-of-school, weekend, or summer camp activities (Benitti, 2012). This is arguably the case in Turkey also due to the expansion of robotic kits available, which has seen a significant increase in the use of educational robotics projects in middle and high school competitions organized by The Scientific and Technological Research Council of Turkey (TUBITAK). With the popularization of the STEM/STEAM approach in education, many teachers want to have training in the field of robotics and coding, and not only IT teachers, but also science and mathematics teachers. This training is available from the in-service courses provided by the Ministry of National Education, as well as from private courses.

Benitti (2012) stated that the United Nations Economic Commission for Europe and the International Federation of Robotics has reported a large increase in the robotics products available for educational purposes and that this increase is estimated to continue for the next few decades. Similarly, OECD reports show that the amount of investment in technology is impressive in order to facilitate its adoption by the school sector although this does not correspond to the acceptance of technology by the teachers and students, nor their integration into educational activities (OECD, 2008). This problem of the acceptance and integration of technology emphasizes the importance of the present research study in relation to teacher education by illustrating the need for training of both teachers and students in order to facilitate the transition from technology installation to technology integration.

Out of the technology used as cognitive tools mentioned above, robots/robotics is particularly special in that it brings programming to life. Using robots in education has undergone great changes. In the beginning, it was only possible to make limited movements (such as going forward or backward, and rightward or leftward) by means of the codes written in LOGO (Papert, 1993) before these objects were transferred to the computer screen. Afterward, 
these objects moved from the virtual world into the real world again. This enabled students to program some machines and even robots (Ucgul \& Cagiltay, 2014). The facilitation of the demanding technical processes has caused robotics and programming to be more popular within education. For this reason, learning environments should be designed to make students experience robotics as cognitive tools in the learning process. As a result of these learning environments, students can construct their own meaningful projects, experience fabrication, and tinkering, as well as design and create interactive objects (Eteokleous, 2018). Papert (1993) noted that robotics is a suitable tool for implementing constructivist-learning principles.

As far as the literature is concerned, the popularity of robotics and programming are increasing in educational environments (Alimisis, 2013; Xia \& Zhong, 2018; Ucgul \& Cagiltay, 2014; Hubwieser et al., 2015; Karim, Lemaignan, \& Mondada, 2015; Mosley, Ardito, \& Scollins, 2016; Özdemir, Çelik, \& Öz, 2009). The literature review suggested that improving learning for ICT teachers enrolled in the "Embedded Systems and Robotic Applications" course at the graduate level was important. In this context, the purpose of this study was to design an authentic learning environment in which educational robotics was used as a cognitive tool in a graduate level course while considering three factors: the literature review, the practitioners' views on teaching educational robotics, and the participants' needs and expectations. In accordance with this purpose, the research questions were constructed as:

- What are the practitioners' views on teaching educational robotics? (Phase 1)

- What are the general characteristics of the learners in terms of prior knowledge, motivation, needs, and expectations through the course? (Phase1)

- What should be done in the design and implementation of the learning environment according to the principles of authentic learning? (Phase 2, Phase 3)

- What are the learners' reflections about the learning environment after the implementation process? (Phase 4)

As explained above, educational robotics is a dynamic field in which new hardware and software tools are constantly emerging. The pedagogical approach and methods used in this research such as cognitive tools, authentic learning, needs analysis, and adaptive scaffolding are important because they are an innovative approach that can solve the problems arising from these changes.

\section{Method}

\subsection{Research Design}

A design-based research approach was employed for the present research as it was conducted throughout the semester. Wang and Hannafin (2005) argued that design-based research has great potential in designing technology-enhanced learning environments through its alternative approach emphasizing concurrent improvements in research, theory, and practice (which are similar components as instructional design activities). Similarly, a design-based research approach in educational technology was proposed by Reeves (2006) consisting of four phases. In this study, a framework was developed modifying the models proposed by Reeves (2006), as well as Wang and Hannafin (2005). This framework was adopted for the context and purpose of the research. Some modifications were made in phase 1 by taking participants' characteristics and needs into consideration, and in phase 3 by adjusting the scaffolding level for each participant during implementation. The research framework can be seen in Figure 1. 


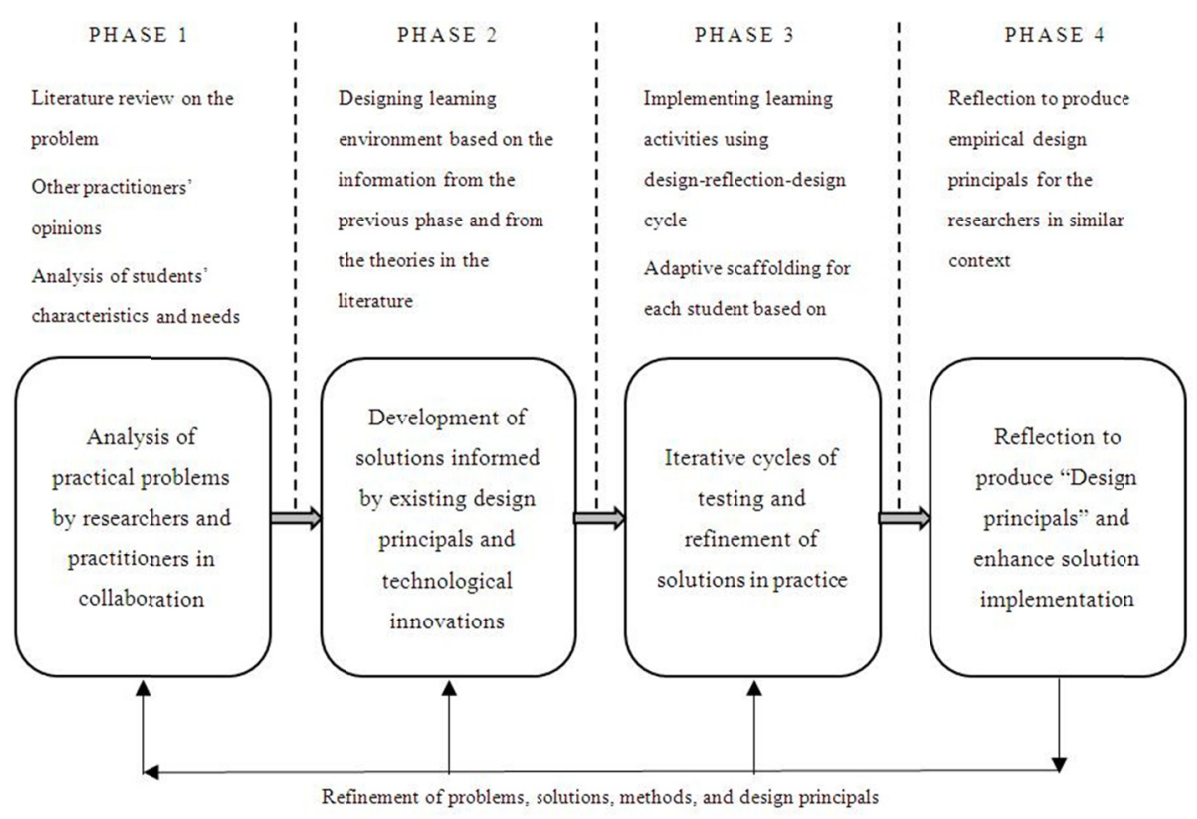

Figure 1. Research Framework, which was adapted from a design-based research approach in educational technology research (Reeves, 2006; Wang \& Hannafin, 2005)

The key elements of the model are that practitioners are researchers' valuable partners, that tested design principals are important in learning environment design, and the need for iterative cycles. Furthermore, the outcomes of the design-based research are based on the contextual design principles for future implementations (Amiel \& Reeves, 2008).

\subsection{Participants}

In the Spring term of 2018, six ICT teachers who graduated from Computer Education and Instructional Technologies participated in this study. Participants' age ranged from 22 to 25 years old. They were attending a graduate course called "Embedded Systems and Robotic Applications" throughout the research process. Therefore, a convenient sampling method was used. Participants' demographic data are presented in Table 1.

Table 1. Participants' demographic data

\begin{tabular}{ll}
\hline $\begin{array}{l}\text { Participant } \\
\text { (Student) }\end{array}$ & Gender, graduated school and occupation \\
\hline P1 & Male, graduated from a vocational high school and CEIT* department, working part-time in a unit within the university \\
P2 & Female, graduated from a general high school and CEIT department, working as an ICT teacher at a private school \\
P3 & Male, graduated from a vocational high school and CEIT department \\
P4 & Female, graduated from a vocational high school and CEIT department, working as an ICT teacher at a private school \\
P5 & Male, graduated from a vocational high school and CEIT department, working as an ICT teacher at a private school \\
P6 & Male, graduated from a vocational high school and CEIT department \\
\hline
\end{tabular}

* CEIT: Computer education and instructional technologies department.

Table 1 shows a total of six participants, four males and two females, who completed their undergraduate education in the CEIT department. Only one of the participants (P2) graduated from a general high school, whereas the other five (P1, P3, P4, P5, and P6) graduated from vocational high schools. Three of the participants (P2, P4, and P5) work as ICT teachers at private schools, P1 works part-time in a unit within the university, and two of the participants (P3 and P6) are unemployed.

\subsection{Qualitative Analysis}

In parallel with the aim of this study, a design-based research approach, and the theoretical foundations of authentic learning, an action research design was put in place while collecting and interpreting the qualitative data. Action research can be used by educators to solve a local problem in the classroom setting. In order to develop a 
plan to solve these problems based on their findings, the researchers or educators participate in the learning and collect the information through their observations, field notes, video recordings, and interviews (Creswell, 2017). The data collection tools developed in the present study are summarized in Table 2.

Table 2. Data collection tools

\begin{tabular}{ll}
\hline Time Period & Data Collection Tools \\
\hline Before the Course & $\begin{array}{l}\text { Practitioners' views on teaching educational robotics } \\
\text { Semi-structured interview form for needs analysis }\end{array}$ \\
\hline During the Course & Observations and video recordings \\
\hline After the Course & Semi-structured interview form for participants' views \\
\hline
\end{tabular}

Before the course, an academic discussion was held regarding the teaching of educational robots with two subject-matter experts with more than 10 years' experience in educational technologies teaching the same courses in different universities. The discussions took approximately one hour. The audio recordings of these discussions and the problems experienced by the subject-matter experts regarding teaching educational robotics were revealed through the themes determined by a common agreement.

A semi-structured interview form, utilized before the course to analyze the participants' characteristics and needs, was developed by the researcher. This form was finalized in line with the opinions of the same two experts. There were 16 open-ended questions in the form. Interviews were conducted with the participants prior to the course using the form, and these interviews were recorded using a voice recorder. Interviews ranged from 20 to 45 minutes. After the voice recordings were converted to text, the participants' answers were coded under three themes according to the common agreement of the researcher and one of the experts. The inter-rater reliability coefficient was calculated as.90. The questions of this form were presented below.

1) Can you tell us about your education background?

2) Do you live with your family?

3) Where are you staying?

4) Do you have an occupation besides your education?

5) Have you attended a robotic course before? Please describe your experience on this subject.

6) Do you have any information about robotic hardware or software? Can you explain the level of your knowledge on these topics?

7) Have you done any research on the subject of robotics before the course?

8) Are you feel comfortable about programming courses? Why?

9) Have your peers or other people had an impact on your self-efficacy level on programming in the past? How?

10) What were the positive or negative experiences you had in programming courses? How did it affect you? (Physiologically)

11) In your opinion, what is the difficulty level of Programming-based courses in the CEIT curriculum compared to other courses?

12) Have you been successful in programming based courses in the past?

13) Do you believe that you will be successful in this course? Why?

14) Can you explain the reasons for choosing this course?

15) (If he/she offers more than one reason) If there is more than one factor in choosing the lesson, which factor do you think is the most important?

16) What are your expectations from the course? What would you like to know or be able to do at the end of the course?

17) How do you think this course should be taught? (What should the pedagogical approach be? What should teachers and students do, should they have homework/projects etc.?)

The observations for every week, as well as the video recordings, which were captured in the last four weeks of the course period, were used as additional data sources during the course. The average duration of the video recordings 
was 80 minutes per week. In Phase 3, in-class observations were used to make arrangements on a weekly basis in accordance with participants' needs in an authentic learning environment. Video recordings were used to determine the participants' motivation in the course, their interactions with their teachers and peers, and the scaffolding level to be presented by the instructor.

After the course period, the second semi-structured interview form was administered in order to gain the participants' views on their experience. This form was finalized according to the opinions of the same experts. There were 7 open-ended questions in the form. After the course, the participants were interviewed by using this form, and these interviews were recorded using a voice recorder. Interviews ranged from 20 to 35 minutes. After the voice recordings were converted to text, the participants' answers were coded under six themes according to the common agreement of the researcher and one of the experts. The inter-rater reliability coefficient was calculated as.95. The questions of this form were presented below.

1) How would you describe the pedagogical approach applied in this course? Does this approach differ from other traditional methods?

2) Do you think that the learning content shared with you from the web environment related to the course were sufficient? How did you take advantage of them? Please explain in your own words.

If the answer is yes:

What else could be done to make the shared content more efficient?

If the answer is no and he/she did not explain the reason in the answer

What do you think about the missing aspects of the content? What are your suggestions to improve the learning content?

3) When you evaluate the instructor of the course in general, do you think that you have had enough support in the course? Was the help and support sufficient when you faced with a problem?

If the answer is yes:

What else do you think that can be done to improve this support further?

If the answer is no and he/she did not explain the reason in his answer:

What do you think that the instructor should have done?

4) Did your peers contribute to your learning during the whole course? How?

5) What strategies did you use to solve the problems you encountered while developing your projects? (Which one do you think is the most effective?)

6) Do you think that you have gained enough knowledge and skills when you think about the learning experience in this course? Please explain.

If the answer is yes:

What were the factors that affected you to gain sufficient knowledge and skills? (Which one was the most influential factor?)

If the answer is no:

What were the factors that affected your inability to gain sufficient knowledge and skills? (Which one was the most influential factor?)

7) Would you compare your motivation to the course at the end of the semester with your motivation at the beginning?

If motivation has increased: What were the reasons for the increase of motivation and which one was the most important?

If motivation has decreased: What were the reasons for the decrease and which one was the most important?

\subsection{Reliability and Validity}

In order to increase the reliability and validity of this research, the following precautions were taken. Within the scope of qualitative data analysis, construct validity was provided by taking two experts' opinions to finalize the semi-structured interview forms. Different data sources such as observations, interviews, participants' reflections, and video recordings were used in order to collect more detailed and explanatory qualitative data. Two participants' opinions about the interpretation of the results were taken in order to provide member checking. In 
addition, the data was presented systematically and was archived so that it could be accessible at the request of external researchers.

\subsection{Ethical Issues}

At the beginning of the research, participants were informed that personal information would be made confidential in the research report and would not be shared with any institutions or organizations. In addition, a voluntary participation form was signed by all participants. Since the researcher was also the instructor of the course, and in order not to affect the participants' responses, a second semi-structured interview form was carried out after the semester.

\section{Results}

\subsection{Phase 1-Clarifying the Problem with Practitioners and Conducting Learner Analysis}

The focus of phase 1 was on the analysis of the problems in the field of the study. In this phase, the problem of the study was clarified considering the information gained from the relevant literature, the opinions of other subject matter experts, and the characteristics and needs of the participants.

\subsubsection{Subject Matter Experts' Views on Teaching Educational Robotics}

As explained under the "Qualitative Analysis" section above, the problems encountered in the field of educational robotic instruction emerged under two main themes: (1) when direct instruction is preferred, the students have difficulty in transferring their knowledge and skills to the problems they face in real life; and, (2) the individual differences that exist in terms of pre-knowledge levels, motivation toward the lesson, and expectations from the course. Some quotations from experts' ideas are presented below.

In the teaching of educational robotics, direct instruction does not constitute meaningful and permanent learning. Students are not able to learn deeply because they only consider the subjects within the scope of exam anxiety. (SME1).

In the educational robotics course, when the students do the projects that includes real life problems, they establish a relationship between the subjects and their real-life needs. In this way, they learn the subjects more and this increases their motivation to the course (SME2).

... in these projects, students have the opportunity to learn cooperatively with their peers and this enables them to see different perspectives in solving problems (SME1).

One of the problems in our field of ICT is the differences between the students' prior knowledge levels. The widespread use of technology enables students to access information and technology tools at different levels in out-of-school environments, which in turn leads students to achieve course objectives in informal learning environments. This brings the teacher face to face with a heterogeneous class in terms of pre-knowledge, expectations, and motivation. (SME3)

\subsubsection{Learner Analysis-Prior Knowledge Levels of the Participants}

It was very important to determine the preliminary knowledge levels of the participants about the course. According to Tobias (1994), there is a substantially linear relationship between prior knowledge and interest, as well as motivation. According to participants' responses in the semi-structured interview form administered before the beginning of the course, it was found that they had not attended a robotics course before. Although most of them had prior knowledge of programming, participants had no idea about the hardware component of robotics. Some of the participants' responses are given below:

I did not attend robotics courses before. I got programming lessons. I searched the robotics software and hardware through video courses on the internet. I have a low level of knowledge about the software part of robotics but I do not have any hardware knowledge (P1).

I did not attend robotics courses before. I do not currently have any knowledge of robotic software and hardware, but I will be giving these lessons at the school I am currently working (P2).

I will take lessons on robotics for the first time. I did some research on the web about robotics. Besides that, we talked to our classmates on this subject. I do not know anything about robotic hardware, but I am a bit familiar with software (P3).

I did not take the robotics course but I attended a 1-day workshop. We bought robotic kits in the school I work for. I have done some search on the internet (P4).

I did not take a robotics course, but I have observed teachers working on robotics at the school I work 
for. I am good at the software but I do not know the hardware at all (P5).

I did not take the robotics course but I joined video-based courses from the internet. I have basic knowledge of robotic software and hardware (P6).

\subsubsection{Learner Analysis-Motivation of Participants to the Course}

The participants were asked why they chose this elective course, and the responses showed that the source of motivation for the participants was due to "the importance of robotics in professional life" (P2, P3, and P4) and "self-improvement" (P1, P4 and P6).

Actually, I did not need to take this course for my graduation, but I took it as an extra course because I want to learn robotics (P1).

Robotic coding is now the first priority of all private schools and public schools (P2).

I think that this course will have a positive effect on my professional life (P3).

I want to learn robotics. I want it for both for my professional life and to produce a real-world product (P4).

Because robotics stands as an open space, also it seems to be a star ready to shine (P5).

... but the main reason for choosing the lesson is that I want to improve myself (P6)

\subsubsection{Learner Analysis-Needs and Expectations from the Learning Environment}

In order to meet the participants' needs and expectations, the participants were asked: "What are your expectations from this course? What do you want to know or do at the end of the lesson?" and "How do you think this course should be handled? (What should the instructor and participants do?)." It is clear from the responses that all the participants preferred a student-centered pedagogy. In addition, two of them (P2 and P6) emphasized that the teacher should use direct instruction until the participants acquired the necessary knowledge and skills. The importance of "practice" was stressed by all the participants. Furthermore, two participants mentioned the "real-world context" through designing a real robot.

The learning environment should be designed as student-centered where the teacher acts as a guide, and students should transfer theoretical knowledge into practice (P1).

Until participants acquire necessary theoretical information, the learning environment should be teacher-centered, then, a student-centered pedagogy should be adopted. I would like to learn about electronic systems related to hardware. I want to be able to do real-world applications using robotics (P2).

It should be an environment that provides student-centered and problem-based learning. At the end of the lesson, I want to be able to design a real robot. I would like to be able to use robotic hardware and software effectively (P3).

It must be an environment that I can learn doing by myself and practicing. A large number of applications should be made in the course (P4).

I would like to have a learning environment based on the basic principle that knowledge is constructed in the mind of the learner. I prefer to have the course including many small projects made by participants (P5).

I think the instructor should provide the basic information at the beginning. When participants gain sufficient knowledge and skills, they can make individual or group projects. This is because there can be some participants who have no prior knowledge of robotic coding in the course (P6).

\subsection{Phase 2-Designing the Learning Environment}

The learning environment was designed according to the principles of authentic learning environments (Herrington, et al., 2014), the context of using technology as cognitive tools (Jonassen, 1994), and the findings from Phase 1. The implementation of the principles of authentic learning environments was based on the study conducted by Herrington and Parker (2013), and the principles were adapted to the context of this study. The explanations about adopting the nine design elements of authentic learning environments are specified below:

\subsubsection{Authentic Contexts in Real Life Settings}

The participants bought robotic development kits and used them during the course. Participants were free to choose the type of robotic kits to buy. Some of them preferred what was needed in the schools they work for, others 
already had these tools in the schools, while others bought basic level or advanced level kits. Most of the kits were Arduino based robotic kits. Therefore, the participants performed simple tasks (e.g., writing numbers on a seven-segment display, scanning the matrix keys, etc.) or complex tasks (e.g., making a robot, a car, a distance meter etc.) given their own context.

\subsubsection{Authentic Tasks}

Direct instruction was minimized and carried out only through the first three weeks of the course. After that period, the participants made applications starting from simple tasks. These tasks were developed by participants considering the instructor's recommendations in real-world settings. At the end of the four-week course, the participants created a project (complex task) that would be useful in their daily or professional life.

\subsubsection{Expert Performances}

The researcher used the learning management system of the university to include learning materials such as textbooks, samples of hands-on activities, and links to video lectures on robotics. In addition, a teacher working on robotics in the professional business world was invited to the class. He shared his knowledge and experiences with the participants and answered their questions.

\subsubsection{Multiple Roles and Perspectives}

In the learning management system designed for the course, the diversity of learning was of a high level. Moreover, the participants were encouraged to share their experiences from their practice with their peers.

\subsubsection{Collaboration in Knowledge Construction}

The participants were encouraged to work with their peers while studying, not only on the simple tasks but also on the complex tasks.

\subsubsection{Reflection}

The participants were asked to complete a weekly reflection report while they were working on the tasks. The reports were submitted using the learning management system.

\subsubsection{Articulation}

Articulation was enabled using discussions, peer reviews, and reflection reports in the learning environment.

\subsubsection{Scaffolding}

Since direct instruction was minimized and the class size was small enough, the instructor was able to focus on scaffolding for each participant in this course. The instructor adjusted the level of support for each participant considering the data collected from his observations during the course, video recordings taken for some weeks, and participants' reflections while conducting the tasks.

\subsubsection{Authentic Assessment}

A periodic assessment was achieved for each participant during the simple tasks. Furthermore, they were assessed for the project they created at the end of the course for a real-world context.

In traditional learning environments, students are the passive receivers of information transferred by the teacher. In this study, educational robots were used as cognitive tools instead of technological products in a traditional teaching environment in order to gain knowledge and skills within the scope of the course. In this way, the participants interacted with these tools, activated their mental processes, and gained knowledge and skills by constructing them in their minds in real-life conditions. This enabled the knowledge and skills in the course to be learned more permanently, while at the same time it was open to some non-planned learning. As an example, the participant who worked on the in-room thermometer project (P4) learned the robotic hardware parts, the software development processes, the box design required for home use, and the design changes required for the device to have a longer battery life. The main objective of authentic learning is to develop students' problem-solving skills by making them confront the challenges of everyday life. The nature of educational robotics is well suited to be used as cognitive tools to apply authentic learning principles in learning environments for this purpose.

\subsection{Phase 3-Implementing Learning Activities Using the Design-Reflection-Design Cycle}

In this phase, the learning activities were implemented according to the design principals mentioned in Phase 2. At the beginning of the course, the instructor used a direct instruction method for the first three weeks because participants, in general, did not have enough prior knowledge based on the results from Phase 1, and some of the participants requested it due to their lack of robotics knowledge. In the following weeks, the instructor minimized the transfer of information, and participants made many real-world applications using their robotic kits as 
cognitive tools. In the last four weeks, the participants worked on a project that they could use in their daily life. Table 3 shows the names of these projects.

Table 3. Name of the projects that participants developed at the end of the course

\begin{tabular}{cl}
\hline Participant & Name of the project developed by participant \\
\hline P1 & Bluetooth-controlled car \\
P2 & Bluetooth- and servo-controlled truck \\
P3 & Developing a parking sensor using a distance sensor \\
P4 & Designing an in-door thermometer \\
P5 & Printing the Bluetooth-transmitted audio on the LCD screen (Speech-to-text included) \\
P6 & Temperature and humidity meter device to be used in plant growing \\
\hline
\end{tabular}

The design-reflection-design cycle was achieved considering the reflections from the participants, observations made by the instructor, and the qualitative data from video recordings during the course. This cycle included additions and revisions of learning materials, activities in the learning management system, and adaptive scaffolding for each participant based on his/her conditions and needs. In Figure 2, some examples of small authentic tasks that participants performed are shown.
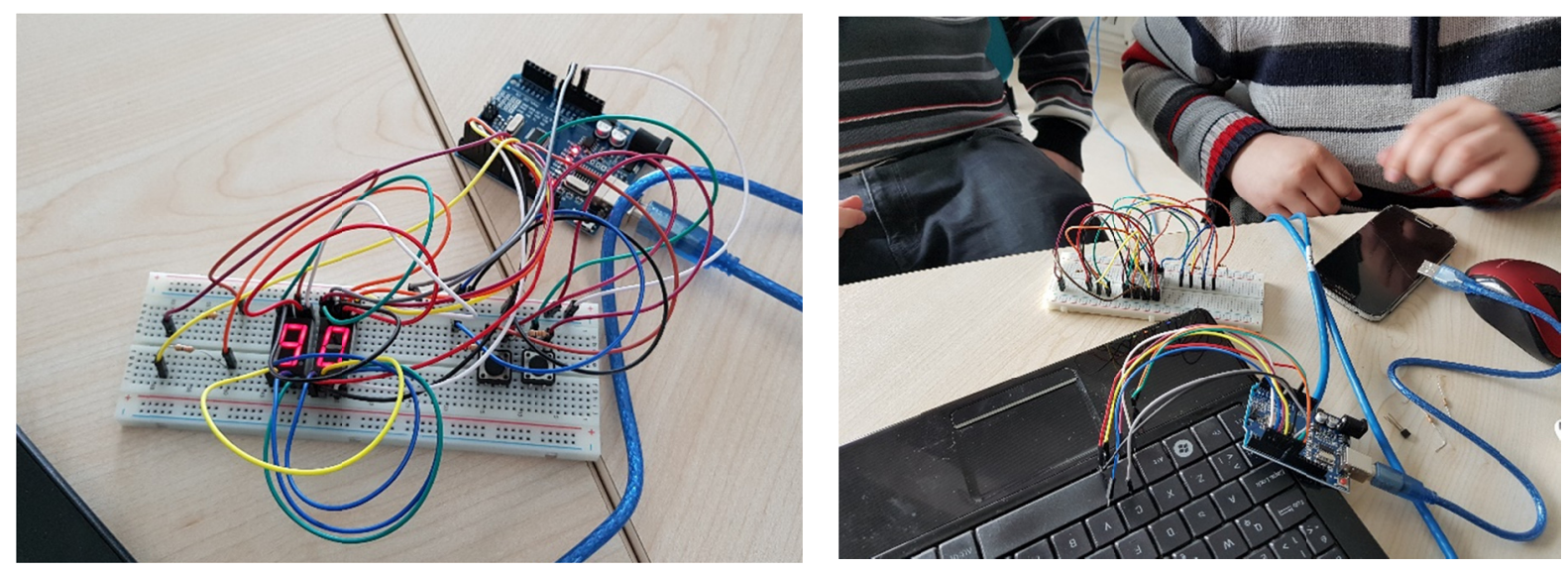

Figure 2. Examples of small authentic tasks performed by participants

\subsection{Phase 4-Reflection of the Research for Similar Contexts}

In order to produce empirical design principles for researchers in a similar context, the participants' responses to the semi-structured interview after the course finished were analyzed. The following emerging themes from the analysis were found:

\subsubsection{Reflections on the Pedagogical Approach Preferred Given the Design of the Learning Environment}

Participants were asked, "How would you describe the methods used in this course? Does it differ from other traditional methods used in other courses?" and their responses show that they had positive opinions regarding authentic learning. Participants emphasized "student responsibility in learning" (P2, P3, P4, and P5), "practices in real-world context" (P2, P3, and P4), and "effective guidance" (P4 and P5).

It was a different experience compared to the other courses. In the first weeks, you gave basic information. Then we made more applications. At the end of the term, we also developed a project. The greatest difference from the other courses was the success in driving us to practice (P2).

A mixed method was used in the course. You used direct instruction in the beginning of the course. Later on, mostly, we worked on the projects, and finally we developed a more complex project searching the internet and collaborating with each other. We worked both in-and-out of the course time. Out-of-class learning activities enabled us to implement practices more effectively during class time (P3). 
The instructor provided effective guidance when we developed practices (P4).

The learning environment designed was different. The instructor helped us discover the solution ourselves (P5).

\subsubsection{Views on Scaffolding Provided by Instructor}

To identify participants' views on scaffolding provided by the instructor, the researcher asked the question "When you evaluate the instructor, do you think that the support provided by the instructor was enough? Please explain in your own words." It is clear from the responses that the participants were satisfied with that support, specifically regarding the application of scaffolding principles.

The support we had when we encountered the problem was sufficient. The knowledge becomes more permanent when we learn ourselves. The instructor provided a comfortable environment in which we could conduct our own learning (P4).

When we encountered a problem in our projects, we received tips from the instructor rather than the complete solution. These directions were sufficient to solve our problems (P5).

I think your support was enough. This is because you gave us a problem situation, and we were trying to work with the learning content you shared in the learning management system (P6).

\subsubsection{Collaboration}

The question "Did your classmates contribute to your learning during the semester? How?" was asked to the participants in order to explore their experiences regarding collaboration. The responses showed that the participants worked with their peers collaboratively to solve the problems they encountered while developing their projects.

Sometimes I got help from my friends to solve the problems we faced while working on the projects. As an example, I could not be successful in writing the text on the LCD screen. I got help from a friend (P3).

Yes, they helped me on the problems in the lesson. We helped each other outside the classroom. I got a lot of support from my friends who had more information from me (P4).

\subsubsection{Problem-Solving Strategies}

The responses to the question "What did you do to solve the problems you faced while developing your project?" indicated that the participants mostly preferred self-directed strategies (P2, P3, P5, and P6), and used the internet as a source of information. As a second strategy, peer and tutorial support was preferred (P4 and P6).

I mostly searched the internet and got some help from my friends (P2 and P3).

Outside the class time, I benefited from my colleagues and instructors for the course (P4).

I mostly used the internet, a bit of the instructor's help as well as my friends' help (P5).

First, I searched the solution in the learning content you shared to us. Then, I tried various sources on the internet such as videos (P6).

\subsubsection{Motivation}

The researcher asked the question "Can you compare your motivation to the course at the end of the session with the motivation at the beginning?" Most of the participants indicated that their level of motivation increased at the end of the course, and the reason being that they had developed projects for a real-world context.

At the beginning of the course, my motivation was high because I thought that I should learn robotics. I had some troubles developing the project, but now I think that I am successful in practice, I plan to develop this project in the future. Making the applications and putting up a concrete project raised my motivation at the end of the course (P2).

I think my motivation through robotics increased after the course. I just came to learn at the beginning of the course. My motivation increased after making a product that we can use in real life (P3).

It absolutely motivated us to develop a project. It a suitable project that we can participate in robotics competitions (P5).

I am planning to work on this subject again in the future (P6). 


\subsubsection{Course Satisfaction}

In order to figure out participants' course satisfaction, the question "Do you think that you gained enough knowledge and skills in this term considering your learning experience in this period? Can you explain?" were asked. The responses proved that they were satisfied with the course. Participants emphasized the concepts of "the projects which are in a real-world context" (P2, P4 and P6), "making practices" (P2, P4), and "small-size class" (P2).

I am satisfied with the fact that the number of participants was small and that we had a practical course and we developed a real-world project (P2).

What I liked most about the course was that there were plenty of practice opportunities. These practices were the kind that I could use at my school (P4).

I benefited from the content shared through the learning management system. I also liked the pedagogical approach that allows learners to learn by self-discovery (P5).

The textbooks and video-based lessons in the learning management system were quite good. We have also developed real-life based projects so that we can learn robotics well (P6).

\section{Conclusion and Discussion}

In this study, a learning environment for a graduate level course "Embedded Systems and Robotic Applications" was designed. The learning environment was designed according to the principles of authentic learning environments (Herrington et al., 2014), in the context of using technology as cognitive tools (Jonassen, 1994), and with consideration to the participants' general characteristics and needs. After the design was completed, the environment was implemented during the Spring 2018 semester and, finally, participants' opinions regarding the implementation of that environment were analyzed.

In order to answer the first and the second research questions, the practitioners' views on teaching educational robotics and the general characteristics of the participants and their needs and expectations for the lessons were explored in Phase 1. The problems encountered in the field of educational robotics instruction emerged under two main themes: (1) when direct instruction is preferred, the students face difficulty in transferring their knowledge and skills to the problems they face in real life, and (2) the individual differences that exist in terms of pre-knowledge levels, motivation toward the lesson, and expectations from the course. In addition, learners' analysis revealed that none of the participants had previous experience in robotics; however, participants did have preliminary knowledge of the software component of robotics due to software courses they had completed in the past. Moreover, they had no idea about the hardware component, which is mostly related to electronics. Regardless, the participants' motivation was high, and the source of this motivation was the job opportunities that robotics could provide them. In addition, the participants stated that they expected to have a student-centered learning environment and wished to take part in the practice, which could develop into projects for the real world. These findings were very important in determining the course of the study.

Phase 1 findings have led to the answer to the third research question. Based on these findings, it was decided that the learning environment should be designed in line with authentic learning principles (Herrington, et al., 2014). Furthermore, the robotic hardware components and software used in the course were not taught to participants through a direct instruction method but were rather used by the participants as cognitive tools. Participants were able to select from many of these technologies and customize them according to their interests applicable to the real-world context. This created a space to spend much more cognitively active time while studying these technologies. Therefore, participants constructed their own understanding about all these technologies, as well as the rationales suggested by Jonassen (1994) such as learning "with" technology rather than "from," learners as thinkers, and knowledge construction rather than reproduction. Considering the participants' final projects, it is obvious that they learned more from the topics covered in the course by researching on the internet or working with their friends collaboratively.

Participants worked on simple and complex tasks in a designed authentic learning environment. When they encountered a problem with these tasks, they had to undergo extensive research on the internet, use the resources in the learning environment system, or collaborate with their peers. In this way, they could take responsibility for their own learning. While the participants were working on these tasks, the instructor provided the support that the participants needed to solve specific problems. This support was adjusted dynamically throughout the semester for each participant. Thus, the instructor established the required scaffolding carefully. As a result, participants were able to solve problems they encountered while working on their projects by discovering and doing it themselves. According to participants' opinions, they were satisfied with the course in that their motivation increased as the 
course continued.

Thanks to the basic principles of authentic learning (Herrington, et al., 2014) used in the design of the course, more time was provided for activities compared to direct instruction. For this reason, the level of satisfaction for the researcher (who was also the instructor of the course) increased as well. The researcher/instructor felt comfortable that he spent his time trying to bring out the creativity of the participants. It is also beneficial to note that the nature of the qualitative research reflects the experience of the researcher as well.

In the context of the last research question, the participants' reflections about the learning environment indicated that their satisfaction levels were good, their motivation increased after the course, and they learned more effectively through the provided scaffolding. The fact that the participants were adults studying at a graduate level and were of a similar age range played an important role in providing effective learning of the proposed learning environment principles in this study. Kirshner, Sweller, and Clark (2006) discussed the importance of guidance in teaching, indicating that guidance begins to lose its importance in students with a high level of pre-knowledge and internal guidance skills, and they argue that students can fail when necessary guidance is not provided. Participants' solutions and their different points of view were challenged when solving problems given the real-life context in which robotics is used as cognitive tools. However, because the pre-knowledge levels required for this course were made available during their undergraduate education, the participants were able to overcome these problems, partly with the help of the well-adjusted instructional guidance. However, the validity and generalizability of the findings obtained in the present study are limited to their own context. Thus, further research should be done in similar contexts for different school levels.

Similar learning environments will be repeatedly implemented for the same course in the future in order to improve the learning environment design strategies that were obtained in this research. In this study, the scaffolding provided by the instructor affected participants' learning positively. Future studies could investigate how to support this scaffolding using learning management systems with artificial intelligence algorithms.

\section{Acknowledgments}

The author likes to thank Enago for the English language review.

\section{References}

Alimisis, D. (2013). Educational robotics : Open questions and new challenges. Themes in Science \& Technology Education, 6(1), 63-71. https://doi.org/10.1007/s12273-008-8106-z

Amiel, T., \& Reeves, T. C. (2008). Design-based research and educational technology: Rethinking technology and the research agenda. Journal of educational technology \& society, 11(4), 29.

Ardito, G., Czerkawski, B., \& Scollins, L. (2020). Learning Computational Thinking Together: Effects of Gender Differences in Collaborative Middle School Robotics Program. TechTrends, 1-15. https://doi.org/10.1007/s11528-019-00461-8.

Benitti, F. B. V. (2012). Exploring the educational potential of robotics in schools: A systematic review. Computers and Education, 58(3), 978-988. https://doi.org/10.1016/j.compedu.2011.10.006

Brown, J. S., Collins, A., \& Duguid, P. (1989). Situated cognition and the culture of learning. Educational Researcher, 18(1), 32-42. https://doi.org/10.3102/0013189X018001032

Creswell, J. W. (2017). Research design: Qualitative, quantitative, and mixed methods approaches. Sage publications.

Derry, S. (1990). Flexible cognitive tools for problem solving instruction. Paper presented at the Annual meeting of the American Educational Research Association, Boston, MA.

Dewey, J. (1938). Experience and education. New York: NY: Touchstone.

Eguchi, A. (2012). What is educational robotics? Theories behind it and practical implementation. In Computers \& Education (Vol. 58, pp. 978-988). https://doi.org/10.1016/j.compedu.2011.10.006

Eteokleous, N. (2018). Robotics and Programming Integration as Cognitive-Learning Tools Encyclopedia of Information Science and Technology (4th ed., pp. 6859-6871). IGI Global. https://doi.org/10.4018/978-1-5225-2255-3.ch594

Herrington, J., \& Parker, J. (2013). Emerging technologies as cognitive tools for authentic learning. British Journal of Educational Technology, 44(4), 607-615. https://doi.org/10.1111/bjet.12048

Herrington, J., Reeves, T. C., \& Oliver, R. (2014). Authentic learning environments Handbook of research on 
educational communications and technology (pp. 401-412). Springer. https://doi.org/10.1007/978-1-4614-3185-5_32

Hubwieser, P., Giannakos, M. N., Berges, M., Brinda, T., Diethelm, I., Magenheim, J., . . . Jasute, E. (2015). A global snapshot of computer science education in K-12 schools. Paper presented at the Proceedings of the 2015 ITiCSE on Working Group Reports. https://doi.org/10.1145/2858796.2858799

Jonassen, D. H. (1994). Technology as cognitive tools: Learners as designers. Paper presented at the ITForum. https://doi.org/10.1007/978-3-642-77222-1_1

Jonassen, D. H., Campbell, J. P., \& Davidson, M. E. (1994). Learning with media: Restructuring the debate. Educational technology research and development, 42(2), 31-39. https://doi.org/10.1007/BF02299089

Karim, M. E., Lemaignan, S., \& Mondada, F. (2015). A review: Can robots reshape K-12 STEM education? Paper presented at the 2015 IEEE International Workshop on Advanced Robotics and its Social Impacts. https://doi.org/10.1109/ARSO.2015.7428217

Kirschner, P. A., Sweller, J., \& Clark, R. E. (2006). Why minimal guidance during instruction does not work: An analysis of the failure of constructivist, discovery, problem-based, experiential, and inquiry-based teaching. Educational psychologist, 41(2), 75-86. https://doi.org/10.1207/s15326985ep4102_1

Lajoie, S. P., \& Derry, S. J. (1993). Computers as cognitive tools. Hillsdale, NJ: Lawrence Erlbaum.

Lindsay, S. (2020). Exploring Skills Gained Through a Robotics Program for Youth with Disabilities. OTJR: occupation, participation and health, 40(1), 57-63. https://doi.org/10.1177/1539449219868276.

Mosley, P., Ardito, G., \& Scollins, L. (2016). Robotic Cooperative Learning Promotes Student STEM Interest. American Journal of Engineering Education, 7(2), 117-128. https://doi.org/10.19030/ajee.v7i2.9895.

OECD. (2008). New Millennium Learners. Initial findings on the effects of digital technologies on school-age learners. Learning in the 21st Century: Research, Innovation and Policy (Vol. 172). https://doi.org/10.3367/UFNr.0178.200809b.0923

Özdemir, D., Çelik, E., \& Öz, R. (2009). Programlama Eğitiminde Robot Kullanımı. Paper presented at the 9th International Educational Technology Conference (IETC2009).

Papert, S. (1993). Mindstorms: Children, computers, and powerful ideas. New York NY: Basic Books, Inc.

Reeves, T. (2006). Design research from a technology perspective. In J. V. D. Akker, K. Gravemeijer, S. McKenney, \& N. Nieveen (Eds.), Educational design research (pp. 52-66). London: Routledge.

Salomon, G., Perkins, D. N., \& Globerson, T. (1991). Partners in cognition: Extending human intelligence with intelligent technologies. Educational researcher, 20(3), 2-9. https://doi.org/10.3102/0013189X020003002

Tobias, S. (1994). Interest, prior knowledge, and learning. Review of educational research, 64(1), 37-54. https://doi.org/10.3102/00346543064001037

Ucgul, M., \& Cagiltay, K. (2014). Design and development issues for educational robotics training camps. International Journal of Technology and Design Education, 24(2), 203-222. https://doi.org/10.1007/s10798-013-9253-9

Wang, F., \& Hannafin, M. J. (2005). Design-based research and technology-enhanced learning environments. Educational technology research and development, 53(4), 5-23. https://doi.org/10.1007/BF02504682

Xia, L., \& Zhong, B. (2018). A systematic review on teaching and learning robotics content knowledge in K-12. Computers and Education, 127, 267-282. https://doi.org/10.1016/j.compedu.2018.09.007

Zhong, B., \& Xia, L. (2020). A Systematic Review on Exploring the Potential of Educational Robotics in Mathematics Education. International Journal of Science and Mathematics Education, 18(1), 79-101. https://doi.org/10.1007/s10763-018-09939-y

\section{Copyrights}

Copyright for this article is retained by the author(s), with first publication rights granted to the journal.

This is an open-access article distributed under the terms and conditions of the Creative Commons Attribution license (http://creativecommons.org/licenses/by/4.0/). 